\title{
Anemia-an Unnoticed Entity in Asian Males A Focus on the Anemic Parameters of Adult Males in Pakistan
}

\author{
Ayesha Nageen $^{{ }^{\star}}$, Saera Suhail Kidwai ${ }^{1}$, Farhat Bashir ${ }^{1}$, Jamal Ara ${ }^{1}$ \\ and Syed Muhammad Munir ${ }^{1}$ \\ ${ }^{1}$ Department of General Medicine, Creek General Hospital, Karachi, Pakistan.
}

Authors' contributions

This work was carried out in collaboration between all authors. Author AN designed the whole study and wrote the manuscript. Authors SSK and FB helped in data collection. Authors JA and SMM supervised the research. All authors read and approved the final manuscript.

Article Information

DOI: 10.9734/BJMMR/2017/33695

Editor(s):

(1) Rui Yu, Environmental Sciences \& Engineering, Gillings School of Global Public Health, The University of North Carolina at Chapel Hill, USA

Reviewers:

(1) Eliana Litsuko Tomimatsu Shimauti, State University of Maringá, Brazil. (2) Dhiraj J. Trivedi, SDM College of Medical Sciences and Hospital, Dharwad, India

(3) Kamal Shemisa, University of Texas Southwestern, USA. Complete Peer review History: http://www.sciencedomain.org/review-history/19379

Original Research Article

Received 26 $6^{\text {th }}$ April 2017

Accepted $1^{\text {st }}$ June 2017

Published $6^{\text {th }}$ June 2017

\section{ABSTRACT}

Background: There is a general lack of awareness that anemia could be present in a significant number of apparently healthy adult males which might then lead to a misdiagnosis and a prolonged suffering of the patient. This study questions the frequency of anemia in healthy adult males which if found high will be an eye opener and an alarm for the doctors.

Aims: This study was to determine the extent of anemia and its related parameters in apparently healthy adult males of a general population.

Study Design: A cross sectional, observational study.

Place and Duration of Study: The research was done in a tertiary care hospital, Creek General Hospital, Karachi from May 2016 to August 2016.

Methodology: we included 493 healthy adult males by convenient sampling. The exclusion criteria included males less than 18 years or with any organ insufficiency, terminal illness or blood dyscrasias or hemoglobinopathies. Complete Blood Count was done to mark anemia and to 
assess its severity. The Mean Corpuscular Volume was categorized as normocytic, microcytic, and macrocytic. The data was analyzed on SPSS version 20.

Results: Out of the 493 males, 238(51.4\%) were anemic out of which114 (47.8\%) were normocytic, $98(41.1 \%)$ were microcytic and $26(11 \%)$ were macrocytic $(P=0.00)$. The severity of anemia among the 238 anemic males showed 164(69\%) males to have mild anemia, 44(18.4\%) to have moderate and $30(12.6 \%)$ to have severe anemia. $(P=.000)$. The mean hemoglobin in males is 12.5 (STD \pm 2.4 ). In younger age group (<30 years) of 210 males, $102(42 \%)$ were anemic. In the middle age group (31- 50 years), out of the 165 that presented $76(46 \%)$ were anemic while 118 patients in the elderly age group (> 50 years), $60(51 \%)$ had anemia $(P=0.72)$. There were 45 diabetic males, out of which $27(60 \%)$ were anemic and among them 20 had mild (74\%) anemia and $18(67 \%)$ were normocytic ( $P=0.049)$. In accordance to ethnicity, in decreasing order, $60 \%$ of Sindhis, $54 \%$ of Pashtuns, $51 \%$ of the Urdu speaking sector, $51 \%$ of Bengalis, $46 \%$ of Gilgitis, $35 \%$ of Punjabis and $22 \%$ of Balouchis were anemic $(p=0.04) .49 \%$ of Muslims, $35.7 \%$ of Christians were anemic. 168 were smokers in which $72(42.8 \%)$ were anemic $(P=0.132)$ with $46 \%$ being normocytic and $33 \%$ being microcytic. Logistic regression did not show any correlation between hemoglobin and age in the study.

Conclusion: Anemia is highly prevalent in the adult males- a fact which has remained unnoticed.

Keywords: Anemia; hemoglobin; males; erythrocyte indices.

\section{INTRODUCTION}

Anemia is a manifestation of an underlying deficiency or illness and its timely identification in apparently healthy individuals could lead to diagnosis of potentially treatable conditions which would otherwise eventually cause significant morbidity or mortality in the future [1]. Anemia when present significantly in a population can directly affect the gross productivity of that population as they will not be able to efficiently contribute as a workforce and hence retarding the economic growth with a loss of Gross Domestic Product. Furthermore, anemia causes a mental deterioration with time which will further slow down human development, education and quality of life [2] Lack of micronutrients leading to anemia has cost a heavy burden on Pakistan which spends estimated three billion dollars on diseases due to micronutrient deficiencies [3]. Anemia is a worldwide health issue with its overall global prevalence in 2010 to be $32.9 \%$ [4] which has only fell by 0.2 to 0.3 percentage points per year between 1993 and 2013 [5].

The high incidence of anemia in females is a globally accepted fact. However, it is overlooked that apparently healthy males may also be suffering from anemia a truth not much considered. This study is to determine the extent of anemia and the related parameters in adult males of the general population who are not suffering from any organ insufficiency.

\section{METHODOLOGY}

The study design was cross sectional, observational and the research was done in an Outpatient clinic of a tertiary care hospital of Karachi from May 2016 to August 2016. The participants included were 493 males from medical clinics above 18 years. The exclusion criteria was age less than 18 years and any severe organ insufficiency, terminal illness or blood dyscrasias at baseline evaluation. Extensive drug history, past history and family history was taken to exclude any known or possible blood disorders and the CBC report was checked for any suspicion of blood dyscrasias or acute hemolytic conditions like malaria and any such found were not included in the study. The study population was selected using a convenient random sampling technique from the outpatient clinics after their given consent. A questionnaire regarding biographic data and required information was filled. Complete blood picture (CBC) was done by $A B X$ Micros 60 Hematology Analyzer to identify anemia and to assess the severity which was divided into mild, moderate and severe. The Mean Corpuscular Volume (MCV) was checked and accordingly noted as normocytic, microcytic, and macrocytic. The data was analyzed on SPSS version 20.

\subsection{Objective Definitions}

\subsubsection{Anemia (WHO criteria) [6]}

Hemoglobin levels in males $<13 \mathrm{~g} / \mathrm{dl}$ 


\subsubsection{Severity of anemia [6]}

Mild; $10-12.9 \mathrm{~g} / \mathrm{dl}$

Moderate; $8.0-9.9 \mathrm{~g} / \mathrm{dl}$

Severe; $<8.0 \mathrm{~g} / \mathrm{dl}$

2.1.3 MCV; [6]

Normocytic; 84-96

Microcytic; $<84$

Macrocytic; $>96$

\section{RESULTS}

Out of the 493 healthy adult males, 238 were anemic (51.4\%).

Anemia categorized according to the age groups is shown in Table 1.

In accordance to the red cell indices, among the 238 anemic males, 114(47.8\%) were normocytic, $98(41.1 \%)$ were microcytic and $26(11 \%)$ were macrocytic. $(P=0.000)$ The severity of anemia was categorized as mild, moderate and severe and its frequency is shown in Table 2.

Anemia classified with respect to ethnicity is shown in Table 3.

Regarding religion, out of 463 Muslims, $226(49 \%)$ were anemic and out of 28 Christians $10(35.7 \%)$ were anemic. The 2 Hindus that presented were anemic (100\%).

There were 45 diabetic males, out of which $27(60 \%)$ were anemic among them 20(74\%) had mild anemia. $(P=.06)$. The anemia was normocytic in $18(67 \%)$ out of the $27(\mathrm{P}=0.049)$ diabetic anemic males.

Among the 493 men, 168 were smokers in which $72(42.8 \%)$ were anemic $(P=0.13)$. The type of anemia in smokers according to MCV is shown in Fig. 1.

\section{DISCUSSION}

The statistics of this research confirmed our suspicion that there is a high incidence of anemia among the healthy adult males of this country - a fact which remains unnoticed. A similar study which was done in Peshawar showed anemia to be at the extent of $67.4 \%$ in healthy males [7] which is even higher compared to our percentage of $51.4 \%$. However, the Mashhadi and Hedayati study in the neighboring country of Iran [8] found much lower incidence of only $6.2 \%$ anemia in adult males while results of a study from Oman [9] showed the frequency of $12 \%$ anemia. The presence of anemia in adult males in our region is based on the lack of balanced diet deprived of micronutrients like iron and foliates. Their staple diet mainly consists of carbohydrate and fat lacking required amount of protein and fresh green vegetables. Other causes can be anemia of chronic disease due to chronic illness like diabetes, worm manifestation due to unhygienic conditions, and occult blood loss due to gastro esophageal ulcerations because of spicy food and excessive intake of drugs like painkillers etc. and antibiotic abuse. According to the World Food Program malnutrition is one the major threats to Pakistan where $24 \%$ being undernourished or malnourished [10]. The mean hemoglobin reported from Peshawar [7] was $11.6 \mathrm{gm} / \mathrm{dl}$ lower than observed in present study $12.5 \mathrm{gm} / \mathrm{dl}$.

Table 1. Anemia present in accordance to the age groups

\begin{tabular}{lll}
\hline Age groups & $\begin{array}{l}\text { Anemia present }(\mathbf{n})(\% \text { of the total that } \\
\text { presented in that group) }\end{array}$ & $\begin{array}{l}\text { Total presented } \\
\text { in that group }\end{array}$ \\
\hline Younger age group (18-30 years) & $102(42 \%)$ & 210 \\
Middle age group (31-50 years) & $76(46 \%)$ & 165 \\
Old age group ( $>50$ years) & $60(51 \%)$ & 118 \\
& $238 \quad P=0.7$ & 493 \\
\hline
\end{tabular}

Table 2. The frequency of anemia according to severity of anemia

\begin{tabular}{lll}
\hline Severity of anemia & Number $(\boldsymbol{n})$ & Percentage $(\%)$ \\
\hline mild anemia $(10-12.9 \mathrm{~g} / \mathrm{dl})$ & 164 & 69 \\
moderate anemia $(8.0-9.9 \mathrm{~g} / \mathrm{dl})$ & 44 & 18.4 \\
severe anemia $(<8.0 \mathrm{~g} / \mathrm{dl})$ & 30 & 12.6 \\
Total & 238 & 100 \\
\hline
\end{tabular}


Table 3.The frequency of anemia in different ethnic groups

\begin{tabular}{llll}
\hline Ethnicity & Anemia present(n) & $\begin{array}{l}\text { \% of anemics out of } \\
\text { the total presented }\end{array}$ & $\begin{array}{l}\text { Total presented in } \\
\text { that group }\end{array}$ \\
\hline Urdu speaking & 130 & 51 & 252 \\
Bengalis & 14 & 51 & 27 \\
Punjabi & 37 & 35 & 104 \\
Sindhi & 24 & 60 & 40 \\
Pushto & 19 & 54 & 35 \\
Gilgit & 12 & 46 & 26 \\
Balouchi & 02 & 22 & 09 \\
Total & 238 & 100 & 493 \\
\hline & & $P=.04$ &
\end{tabular}

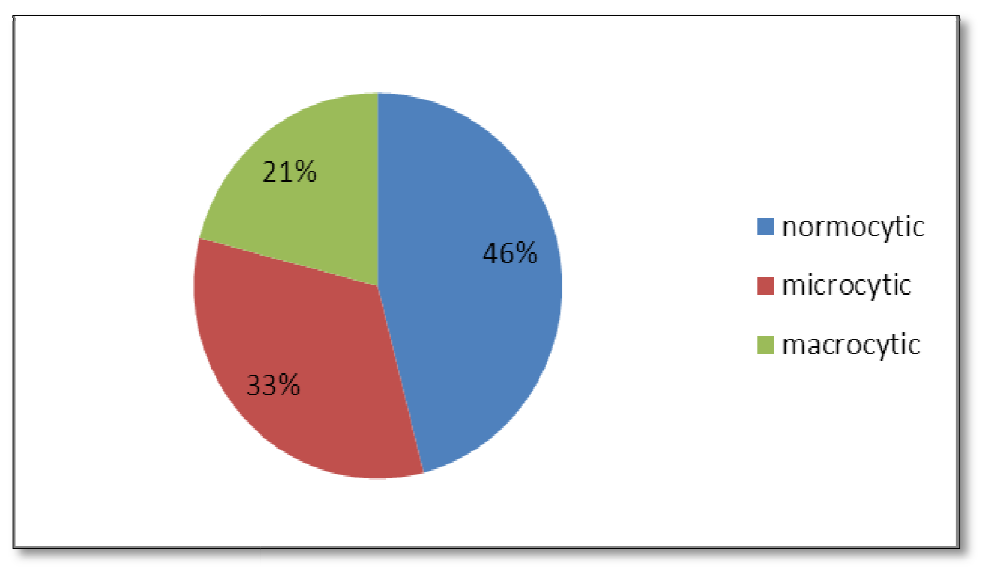

Fig. 1. Type of anemia in smokers according to MCV

$$
(P=.05)
$$

The incidence of anemia increased with increasing age. Anemia in elderly males is more prevalent due to their disturbed diet pattern and lack of a balanced diet. The loss of appetite, malabsorption, malnutrition, presence of gastritis, drug misuse/abuse, the occurrence of co morbids causing anemia of chronic disease are some major reasons for anemia in the elderly group. This fact is seconded by the study of Iran [8] where the elderly males were more anemic than the younger group, and a Brazilian study done on elderly males where the anemia incidence was $10.4 \%$ [11]. Patel compared various studies (mainly of USA and Italy) conducted on prevalence of anemia in elderly males and concluded that prevalence of anemia ranged from $9.2 \%$ to $23.9 \%$ in older men [12].

The statistics showed that the Sindhis, Pashtuns, Urdu speaking and Bengalis are more prone to be anemic (in decreasing order respectively) having a percentage greater than $50 \%$ compared to Gilgits, Punjabis and Balouchis where it is less than $50 \%$.The Peshawar study also confirmed Pashtuns to have a high incidence of anemia [7].
Faruk reviewed anemia's prevalence in Bangladesh and stated that the adult males had a prevalence of $68 \%$ [13] and emphasized on the lack of iron in diet. Apart from the lack of awareness, availability of balanced diet and malnutrition, the Sindhis, Urdu speaking sector, Pashtuns and Bengalis have a strong inclination towards 'Gutka', tobacco, Niswar, etc. aggravating anemia. Pashtuns also have a tendency towards constipation and hence hemorrhoids causing chronic blood loss. Further extension studies would be needed to evaluate the etiology of anemia according to the specific ethnicity.

When considering religious modality, not only Muslims but Christians also had a significant incidence of anemia. These findings reconfirm that the anemia is linked essentially to our dietary habits and lifestyle structure that is particular to this region. The two Hindus in the study were anemic which could be due to religious norms of dietary constraints. However, Milan argued in his Indian study that the prevalence of anemia in Hindus and Non Hindus was similar [14]. 
Majority of healthy adult males in the present study group presented mild form of anemia which could be due to dietary deficiency of micronutrients and can be corrected by targeted dietary management.

The Peshawar study points mild anemia is more common in males [7]. Italian study points mild anemia is common in elderly males [15]. But Indian study by Milan indicates, mild anemia is prevalent in all age group healthy individuals [14].

The results of red cell indices showed prevalence of both normocytic and microcytic form of anemia pointing to the fact that the major cause of concern is the lack of nutrients in diet particularly iron, chronic/occult blood loss due to ulcerations, the excessive consumption of tea and coffee hindering iron absorption. The Peshawar [7], and Indian study are showing normocytic anemia to be more prevalent in males. [16] The presence of macrocytic anemia was plausibly due to the tendency of having overcooked food destroying heat labile vitamins, lesser consumption of green vegetables, and increased predisposition to addiction/alcoholism.

Diabetics are more prone for anemia due to a chronic illness triggering renal compromise causing anemia of chronic disease. The existence of anemia with diabetics worsens the glomerular filtration rate (GFR) and leads to cardiovascular disease. Thus it is cardinal to diagnose and correct anemia in diabetics. An Iranian study on male diabetics showed 9.2\%. [17] Another study on association of diabetics and renal function showed anemia in 19\% diabetics. This emphasize on strict sugar control and correction of anemia as the anemia prevails the GFR declines causing a vicious circle [18] Sharif and Younus showed 27\%of male diabetics are anemic [19] but our results show a much higher rate. The type of anemia in diabetics here was mainly normocytic. In 2015 Nadia and Shams showed $52 \%$ of diabetic males having anemia and $60 \%$ of them were normocytic [20].

It is a physiologically accepted fact that smokers have raised hemoglobin due to secondary polycythemia in response to erythropoietin. The elevation of erythropoietin is caused by hypoxia associated with the increase of carbon monoxide induced by smoking. An Iraqi study [21] comparing the hemoglobin status in smokers vs. nonsmokers found the hemoglobin levels are higher in smokers and suggested to adjust hemoglobin values in smokers as smoking can mask anemia [22]. The high percentage of male smokers with anemia in our study was a surprise and an eye opener because it did not fit with the normal physiological response, implying that there are other overpowering mechanisms which are still causing anemia. Hence anemia in smokers is more sinister. This indirect relationship of anemia and smoking could be due to malignancy changes [23], recurrent chronic respiratory infections $[24,25]$ and iron deficiency anemia because smoking hinders iron absorption [26]. This is understandable because the type of anemia was mainly normocytic and microcytic in smokers of our study.

\section{CONCLUSION}

Hence the study concluded that anemia is a prevailing substantial concern in healthy adult males of a developing country like Pakistan. This is an eye opener and an alarm for the doctors. A timely prompt identification and correction of anemia can help in diagnosis of underlying deficiencies or illness and also augment the recovery to improve the outcome in ongoing management of diseases. A better understanding and further research into the most common etiologies leading to anemia characterization would be an important step towards an effective strategy for dealing with anemia. The best approach to eradicate anemia would be an extensive structured community based stratagem by inculcating public awareness about benefits of balanced diet, mandatory inclusion of fresh green vegetables, meat and iron rich food into the diet and initiation of food fortified products like cereals with micronutrients. Availability and cognizance of routine medical/health checkups for screening and early diagnosis of chronic illness and mindfulness of drug abuse are other points for action. The results of the study can be utilized in a public health program to design targeted intervention aiming to reduce the burden of anemia in our region improving the well being of community along the way.

\section{LIMITATIONS OF THE STUDY}

It was a hospital based study on a considerably limited number of people in which $\mathrm{CBC}$ was done as a routine investigation. A wider scale study should be done on a community basis. We used data from patients coming to the hospital to assess the frequency of anemia in the population. This could have led to an overestimation of anemia. However, we excluded 
patients admitted to the hospital. Limitations of our study also include an inability to know for certain whether patients had underlying hemoglobinopathy or X-linked G6PDH disorder which is known causes for anemia endemic in our region.

\section{CONSENT}

As per international standard or university standard, patient's written consent has been collected and preserved by the authors.

\section{ETHICAL APPROVAL}

The research protocol was approved by the relevant institution's review board and ethical committee.

\section{ACKNOWLEDGEMENTS}

Statistical analysis; we thank for the statistical analysis done by Prof Dr Syed Sanwer Ali.

\section{COMPETING INTERESTS}

Authors have declared that no competing interests exist.

\section{REFERENCES}

1. Jilani T, lqbal MP. Risks associated with mild Anemia in apparently healthy individuals: How to combat Anemia in general population. Pak J Med Sci. 2010; 26(4):990-994.

2. Arielle G. Nutrition in Pakistan. From: Secretary of Health, Pakistan. To: Minister of Finance, Pakistan.

3. Saeed A, Anwaar A, Asif A, Zulfiqar A, Muhammad R, Tariq I. Iron status of the Pakistani population-current issues and strategies. Asia Pac J Clin Nutr. 2013; 22(3):340-347.

4. Nicholas JK, Rashmi J, Mohsen N, Sarah KW, Nicole J, Rafael L, et al. A systematic analysis of global anemia burden from 1990 to 2010. Blood. 2014;123:615-624.

5. Francesco B, Lina MT, Shireen M. The lack of progress in reducing anemia among women: The inconvenient truth. Bulletin of the World Health Organization. 2014;92: 231.

6. Hemoglobin concentrations for the diagnosis of anemia and assessment of severity. VMNIS | Vitamin and Mineral Nutrition Information System. WHO/NMH/NHD/MNM/11.1.
Available:http://www.who.int/vmnis/indicato rs/haemoglobin.pdf?ua=1

7. Shahab F, Sikandar S, Shahab A, Raziq F. Frequency of anemia in patients presenting to tertiary care hospital in Peshawar, Pakistan. Khyber Med Univ J. 2015;7(1):30-33.

8. Eftekharzadeh-Mashhadi I, HedayatiMoghaddam R, Farhad F, Bidkhori HR, Shamsian SK. Anemia as a public health Issue in Mashhad, Iran: Evidence from the first population-based study. Acta Medica Iranica. 2015;53(3):186-190.

9. Report on the study of food fortification In Oman. Ministry of Health, Sultanate of Oman.

Available:http://www.moh.gov.om/reports/F FFS report draft October 09.pdf

(Accessed in August 2016)

10. Countries: Pakistan. Facts and Figures. World Food Program; 2010.

Available:http://www.wfp.org/countries/paki $\underline{\text { stan }}$

11. Sgnaolin V, Engroff $P$, Ely LS, Schneider $\mathrm{RH}$, Schwanke $\mathrm{CH}$, Gomes I, Morrone FB, de Carli GA. Hematological parameters and prevalence of anemia among freeliving elderly in south Brazil. Rev Bras Hematol Hemoter. 2013;35(2):115-8.

12. Patel KV. Epidemiology of anemia in older adults. Semin Hematol. 2008;45(4):210-7.

13. Faruk A. Anemia in Bangladesh: A review of prevalence and etiology. Public Health Nutrition. 2000;3(4);385-393.

14. Milan J, Surabhi P. Prevalence of anemia and its associated sociodemographic factors in apparently healthy individuals presenting as prospective blood donors at a Medical Institute of Rohilkhand region. Int J Med Sci Public Health. 2017;6.

15. Mauro T, Ugo L, Francesca G, Angela R, Paola M, Giovanni A, et al. Prevalence, incidence and types of mild anemia in the elderly: The "Health and Anemia" population-based study. Haematologica. 2010;95(11):1849-1856.

16. Gerardo A, Praveen KN, Manoranjan M, Pradeep SY, Raghavakalyan P. Prevalence and severity of anemia stratified by age and gender in rural India. Anemia; 2014. Article ID 176182.

17. Bonakdaran S, Gharebaghi M, Vahedian $M$. Prevalence of anemia in type 2 diabetes and role of renal involvement. Saudi J Kidney Dis Transpl. 2011;22:28690. 
18. Alemayehu A, Wubet B., Abebe A. Association of anemia and renal function test among diabetes mellitus patients attending Fenote Selam Hospital, West Gojam, Northwest Ethiopia: A cross sectional study. BMC Hematology. 2013; 13:6.

19. Sharif A, Younus S, Baig K, Ali N. Prevalence and risk of anemia in type-2 diabetic patients. Health. 2014.6;14151419.

20. Nadia S, Osmani MH. Newly diagnosed anemia in admitted diabetics, frequency, etiology and associated factors. JCPSP. 2015;25(4):242-246.

21. Payam OH, Rezman AA, Kowan M, Ibrahim D, Hemn M, Sarkawt $\mathrm{HH}$. Cigarette smoking risks on blood indices and liver enzymes of male and female smokers in Kurdistan, Iraq. JJBS. 2015; 8(3).
22. Ashish G, Desh D, Naveen G. Study of relationship of tobacco smoking with hemoglobin concentration in healthy adults.JPBMS. 2010;01(19).

ISSN: 22307885

23. Majid S, Saiprakash V. Hematologic abnormalities associated with lung carcinoma. Respiratory Care. 2011;56(4): 523-526.

24. Michael C, Lisa W, Derek CA, John AK, Eric BM. The prevalence of anemia and its association with 90-day mortality in hospitalized communityacquired pneumonia. BMC Pulm Med. 2010;10-15

25. Marcos Borato V. Anemia and infection: A complex relationship. Rev Bras Hematol Hemoter. 2011;33(2):90-92.

26. Michelle M. Smoking \& iron levels; 2015. Available:http://www.livestrong.com/article/ 233579-smoking-andvitamin-absorbtion

(0) 2017 Nageen et al.; This is an Open Access article distributed under the terms of the Creative Commons Attribution License (http://creativecommons.org/licenses/by/4.0), which permits unrestricted use, distribution, and reproduction in any medium, provided the original work is properly cited. 